\title{
ENSINO DE HISTÓRIA, PATRIMÔNIO E PRÁTICAS EDUCATIVAS DECOLONIAIS NO MUSEU DE PERCURSO DO NEGRO DE PORTO ALEGRE ${ }^{1}$
}

Arilson dos Santos Gomes ${ }^{2}$

\begin{abstract}
Resumo: O presente trabalho visa problematizar o ensino de história, o patrimônio e as práticas educativas decoloniais desenvolvidas na formação de jovens negros e quilombolas no âmbito das atividades do Museu de Percurso do Negro de Porto Alegre, capital do Estado do Rio Grande do Sul. Por meio da observação participante, cotejadas com fontes imagéticas e bibliografia pertinente à luz da Museologia Social, pode-se constatar as possibilidades de ensino de história e da cultura afro-brasileira em espaços comunitários a partir da vivência e da produção de saberes dos sujeitos envolvidos.
\end{abstract}

Palavras-Chave: Museu de Percurso do Negro; Museologia Social; Ensino de História; Patrimônio; Prática Decolonial.

\section{HISTORY TEACHING, HERITAGE AND DECOLONIAL EDUCATIONAL PRACTICES IN THE MUSEUM OF THE PATH OF THE BLACK POPULATIONS OF PORTO ALEGRE}

\begin{abstract}
The present work aims at to problematize the teaching of history, heritage and the decolonial educational practices developed in the formation of young black and quilombolas in the scope of the activities of the Black Path Museum of Porto Alegre, capital of the State of Rio Grande do Sul. Through participant observation, collated with imagery sources and pertinent bibliography in the light of Social Museology, one can verify the possibilities of teaching history and Afro-Brazilian culture in community spaces based on the experience and the production of knowledge of the subjects involved.
\end{abstract}

Key words: Black Route Museum; Social Museology; History Teaching; Education; Heritage; Decolonial Practices.

\section{HISTORIA DOCENTE, PATRIMONIO Y PRÁCTICAS EDUCATIVAS DECOLONIALES EN EL MUSEO DE LA RUTA DEL NEGRO EN PORTO ALEGRE}

Resumen: El presente trabajo tiene como objetivo problematizar la enseñanza de la historia, el patrimonio y las prácticas educativas descoloniales desarrolladas en la formación de jóvenes negros y quilombolas dentro del alcance de las actividades del Museo de la Ruta del Negro en Porto Alegre, capital del estado de Rio Grande del Sur. A través de la observación participante, en comparación con las fuentes de imágenes y la bibliografía pertinente a la luz de la

\footnotetext{
${ }^{1}$ Este trabalho é uma revisão atualizada e ampliada do capítulo publicado originalmente no livro em formato ebook: $O$ ensino de história da África e da cultura afro-brasileira e indígena: múltiplos olhares, da Editora UNEMAT, 2018.

${ }^{2}$ Docente do Mestrado Interdisciplinar em Humanidades (MIH-UNILAB) Professor dos Cursos de Antropologia e de Humanidades da Universidade da Integração Internacional da Lusofonia Afro-Brasileira (UNILAB). E-mail: arilsondsg@yahoo.com.br
} 
Museología Social, es posible verificar las posibilidades de enseñar historia y cultura afrobrasileña en espacios comunitarios a partir de la experiencia y la producción de conocimiento de los sujetos involucrados. .

Palabras clave: Museo de la Ruta Negra; Museología social; Enseñanza de la historia; Patrimonio; Práctica descolonial.

\section{INTRODUÇÃO}

O presente trabalho visa problematizar o ensino de história, o patrimônio e as práticas educativas desenvolvidas na formação de jovens negros e quilombolas no âmbito das atividades do Museu de Percurso do Negro de Porto Alegre, capital do Estado do Rio Grande do Sul. Por meio da observação participante, cotejadas com fontes imagéticas e bibliografia pertinente à luz da Museologia Social, pode-se constatar as possibilidades de ensino de história e da cultura afro-brasileira em espaços comunitários a partir da vivência dos sujeitos envolvidos.

A formação de jovens, oriunda da execução do projeto do Museu de Percurso do Negro de Porto Alegre, foi realizada entre os anos de 2009 e 2014 e teve como meta a formação de monitores para atuarem como mediadores/guias das atividades de ação educativa de um museu diretamente relacionado com a história das populações negras. Diante disso, enfatiza-se a importância das políticas de Ações Afirmativas para a execução do projeto do museu e no desenvolvimento das demais atividades concernentes a ele. ${ }^{3}$

A missão do Museu é valorizar as dinâmicas da população negra de Porto Alegre através da práxis museológica, da pesquisa, da preservação e da comunicação combatendo a invisibilidade do patrimônio material e imaterial desta comunidade. Evidencia-se que ao versar sobre museus deve-se, necessariamente, aludir às coleções.

\footnotetext{
${ }^{3}$ De acordo com o Grupo de Estudos Multidisciplinares da Ação Afirmativa (IESP/UERJ) as Ações afirmativas são políticas focais que alocam recursos em benefício de pessoas pertencentes a grupos discriminados e vitimados pela exclusão sócio-econômica no passado ou no presente. Trata-se de medidas que têm como objetivo combater discriminações étnicas, raciais, religiosas, de gênero ou de casta, aumentando a participação de minorias no processo político, no acesso à educação, saúde, emprego, bens materiais, redes de proteção social e/ou no reconhecimento cultural. No contexto dessas ações, em 2003, foi decretada a Lei n 10.639, que instaurou a obrigatoriedade do ensino sobre História e Cultura Afro-Brasileira nos currículos escolares. No ano seguinte, foram criadas as Diretrizes Curriculares 03/2004, documento que versa sobre as Diretrizes Curriculares Nacionais para a Educação das Relações Étnico-Raciais e para o Ensino de História e Cultura Afro-Brasileira e Africana, demonstrando que essas políticas tencionaram elementos propositivos profundos na educação brasileira para além da discussão de cotas no Ensino Superior. Inclusive, nas diretrizes curriculares citadas consta a necessidade de Políticas de reparações voltadas para a valorização do patrimônio histórico-cultural afro-brasileiro (BRASIL, 2004, p.11). Assim como aborda, como princípio, a importância das ações educativas de combate ao racismo e às discriminações por meio da "educação patrimonial e do aprendizado a partir do patrimônio cultural afro-brasileiro, visando a preservá-lo e difundi-lo” (BRASIL, 2004, p.19).
} 
A categoria "colecionamento" traduz, de certo modo, o processo de formação de "patrimônios". Sabe-se que estes, em seu sentido moderno, podem ser interpretados como coleções de objetos móveis e imóveis apropriados e expostos por determinados grupos sociais. De acordo com José Reginaldo Santos Gonçalves, em seus estudos sobre a antropologia dos objetos, todo e qualquer grupo humano exerce algum tipo de atividade de "colecionamento" de objetos materiais cujo efeito é demarcar um domínio subjetivo em oposição a um determinado "outro". O resultado dessa atividade é precisamente a constituição de um "patrimônio" (GONÇALVES, 2007, p.108).

Nesse artigo a categoria de patrimônio se vincula à materialidade elaborada e significada pela comunidade negra porto-alegrense de maneira positiva de modo a desconstruir aspectos da colonialidade que, por meio dos estereótipos e estigmas, reproduzidos com as peculiaridades locais, marginaliza as contribuições dessas populações na formação da cidade. ${ }^{4}$ Diante disso, o museu tem como itinerário os espaços territoriais da cidade e a sua coleção, guardas as proporções, são os marcos monumentalizados, a céu aberto, em bairros, praças, igrejas, ruas, esquinas e no mercado público central, que preservam a memória desta comunidade.

O Museu de Percurso do Negro de Porto Alegre, por sua relevância e originalidade, à luz da interdisciplinaridade, tem se destacado em recentes publicações, artigos acadêmicos e trabalhos de conclusão de curso de graduação e de pós-graduação nas áreas de Antropologia, Geografia, História, Educação, Sociologia e Museologia (BITTENCOURT JÚNIOR; OLIVEIRA; VILASBOAS, 2010; GONZAGA, 2015; MATTOS, 2013; ROSA, 2019; RUPPENTHAL, 2016; SOARES, 2017; VIEIRA, 2014), da mesma maneira que tem recebido atenção especial da mídia local e nacional. ${ }^{5}$

\footnotetext{
4 “A retórica da modernidade (da missão cristã desde o século XVI, à missão secular de Civilização, para

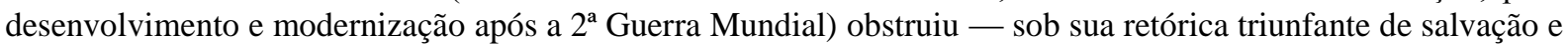
boa vida para todos - a perpetuação da lógica da colonialidade" (MIGNOLO, 2008, p.293). Embora sua narrativa trate de maneira mais objetiva dos povos indígenas na América Latina, o conceito de colonialidade refletido por Mignolo serve-nos para problematizar a trajetória de invisibilidade, material e imaterial, imposta as produções culturais das comunidades negras no estado do Rio Grande do Sul, desde a escravidão ao pós-abolição com influências na contemporaneidade. Ressalta-se que o Estado do Rio Grande do Sul é considerado, em virtude da imigração italiana e alemã, um dos espaços territoriais mais europeizados do Brasil, o que efetivamente acentua as tensões entre a visão hegemônica de mundo ocidental versus as cosmovisões advindas dos povos historicamente marginalizados no advento da modernidade, a exemplo dos grupos negros.

5 Dois documentários foram produzidos pela TV Educativa do RS. Disponível em: $<$ https://www.youtube.com/watch?v=-inSFMJzIMs $>$. Acesso 23 jan. 2018. Em reportagem realizada no dia 20 de novembro de 2016 pela RBS TV, Pedro Vargas, integrante da equipe do museu, apresenta o Museu de Percurso do Negro e um dos monumentos aos telespectadores. Disponível em: <http://g1.globo.com/rs/rio-grande-dosul/noticia/2016/11/museu-de-percurso-do-negro-resgata-memoria-e-territorios-em-porto-alegre.html>. Acesso 28 jan.2018. Um passeio ao Museu de Percurso do Negro também fez parte da programação do $8^{\circ}$ Encontro Escravidão e Liberdade no Brasil Meridional, realizado em Porto Alegre em 25 de maio de 2017. O Encontro é
} 
O projeto, promovido pelo Programa Monumenta do Ministério da Cultura, Instituto do Patrimônio Histórico Nacional (IPHAN), em parceria com a Organização das Nações Unidas para a Educação, a Ciência e a Cultura (Unesco), o Banco Interamericano de Desenvolvimento (BID), o Governo Federal e a gestão da Prefeitura Municipal de Porto Alegre, contou com o apoio da Escola Pública de Saúde do Estado e ficou sob a coordenação geral do Grupo de Trabalho (GT) Angola Janga, organização negra. ${ }^{6}$ As outras entidades negras participantes do Projeto são a Associação Cultural Quilombo do Areal, Instituto de Assessoria ás Comunidades Remanescentes de Quilombos (Iacoreq), Associação dos Amigos do Bairro Cidade Baixa e Arredores (Mocambo) e a Congregação em Defesa das Religiões Afro-brasileiras (Cedrab), RS.

A ação do projeto prevê, por etapas, as construções de marcos/monumentos na cidade e a formação de monitores a fim de se visibilizar a comunidade negra, que se tornou invisível ou estereotipada nos museus da cidade. ${ }^{7}$

Para o desenvolvimento da narrativa, o texto abordará a origem do Museu de Percurso do Negro, o patrimônio e a Museologia Social bem como evidenciará as atividades de ensino de história e as práticas educativas decoloniais desenvolvidas junto aos jovens monitores guias do museu.

\section{O MUSEU DE PERCURSO DO NEGRO DE PORTO ALEGRE, PATRIMÔNIO E A MUSEOLOGIA SOCIAL}

Os primeiros esforços para colocar em prática ações que iriam ser materializadas no projeto do museu aconteceram no final da década de 1990, quando diversas organizações negras do movimento negro porto-alegrense reuniram-se no Museu de Porto Alegre Joaquim Felizardo, da Secretaria Municipal da Cultura, para discutir o I Seminário para organização de

\footnotetext{
uma organização conjunta dos Programas de Pós-Graduação em História da UFRGS, da UFPR e da UFSC e conta com a participação de pesquisadores de todo o Brasil. Essa participação tornou ainda mais visível o Museu de Percurso. Disponível em:< http://www.escravidaoeliberdade.com.br/site/images/8encontro/programa.pdf $>$. Acesso 26 jan.2018.

${ }^{6}$ O GT Angola Janga é uma organização do movimento social surgida em Porto Alegre na década de 1990. Sua principal liderança foi José Alves Bitencourt, o Nêgo Lua, falecido após a execução da primeira etapa do museu. As outras etapas do Museu foram: a segunda, a Pegada Africana (2011), a terceira, a obra de arte Bará do Mercado (2013) e a quarta, a obra de arte pública Painel Afro-brasileiro (2014). Disponível em: <http://museudepercursodonegroemportoalegre.blogspot.com.br/p/textos.html>. Acesso 16 jan.2018.

${ }^{7}$ Conforme Lizandra Maria Rodrigues e Maria Angélica Zubaran os museus tradicionais mantêm uma visão homogeneizada do continente africano, limitam as produções ao caráter religioso e a ênfase no exotismo fetichista e aos objetos da escravidão. As representações são racializadas e construídas com base em estereótipos étnicoraciais do negro que fixam como "naturais" características culturalmente construídas sobre esses sujeitos. Em Porto Alegre, o Museu Julio de Castilhos, em sua Sala Período Escravista onde são expostas imagens de escravizados urbanos, punições no pelourinho além da exposição de objetos como gargalheiras, correntes e troncos, confirma a reflexão das autoras (RODRIGUES; ZUBARAN, 2013).
} 
um centro de referência afro-brasileiro. Espaço que teria por objetivo catalisar associações que desenvolvessem políticas em prol das reivindicações da comunidade negra local (VARGAS, 2013). ${ }^{8}$

De acordo com o relatório antropológico de Iosvaldyr Carvalho Bittencourt Júnior para o Projeto de Implantação do Museu, o modo de vida e a dinâmica das relações negras desde o período da escravidão, nas ruas e no entorno de Porto Alegre, geraram ricos patrimônios culturais (BITTENCOURT JÚNIOR, 2010).

O percurso visual em processo de execução evoca a presença, a memória, o protagonismo social e cultural dos africanos e descendentes no Centro Histórico da cidade de Porto Alegre, cuja pesquisa histórico-antropológica indicou os lugares vivenciados pelos negros, a fim de elaborar objetos de arte representativos, como o Cais do Porto e os antigos Ancoradouros; o Mercado Público e seu entorno; o Largo da Quitanda (Praça da Alfândega); no Pelourinho (Igreja das Dores); no Largo da Forca (Praça Brigadeiro Sampaio); a Esquina do Zaire (Av. Borges de Medeiros com Rua da Praia); a Igreja da Nossa Senhora do Rosário; o Mercado Público; a Santa Casa de Misericórdia; a Colônia África e o Areal da Baronesa. ${ }^{9}$

O processo de criação do Museu de Percurso do Negro em Porto Alegre implica a observação histórica sobre a trajetória da museologia, antes tradicional e voltada para as coleções em espaços edificados para novos conceitos e perspectivas; em que outras compreensões, como a origem da instituição museu no tempo-espaço, bem como as populações e o patrimônio passam a compor o fenômeno observável pela Museologia Social. Segundo Judite Primo:

A Nova Museologia, do ponto de vista dos princípios, não se dirige exclusivamente aos objetos a conservar ou a exibir a um público, mas sim aos sujeitos sociais. No contexto da segunda metade do século XX, o museu foise transformando num centro de expressão da dinâmica social dos grupos que trabalhavam a partir da memória e das referências do passado para a construção da sua identidade (PRIMO, 2014, p.06).

Para Iosvaldyr Carvalho Bittencourt Júnior, em análise aos museus tradicionais:

\footnotetext{
${ }^{8}$ Dessas reuniões, em 2008 foi criado o Museu de Percurso do Negro em Porto Alegre. Desses encontros nasceu em 2009 o projeto Territórios Negros, realizado pela Prefeitura de Porto Alegre através da empresa de transporte público Companhia Carris Porto-Alegrense. O Territórios Negros tornou-se uma ferramenta pela qual os professores podem trabalhar os conteúdos da Lei 10.639/03, lei do Brasil que estabelece a obrigatoriedade do ensino de história e cultura afro-brasileira (GONZAGA, 2016).

${ }^{9}$ Disponível em:<http://museudepercursodonegroemportoalegre.blogspot.com.br/>. Acesso 15 jan.2018.
} 
$\mathrm{Na}$ área da museologia as mudanças tem sido lentas, onde o negro e seus respectivos universos sócio-antropológicos de matriz africana, em geral, são apresentados ou representados de forma coisificada, depreciativa e pontuado por persistentes figuras estereotipadas negativamente, em visão folclorizantes, idealizantes e dissociadas do agente social, consagrando uma espécie de elaboração de múltiplas imagens que impõem uma reducionista objetificação da nadificação ontológica construída sobre os africanos e seus descendentes nas Américas (BITTENCOURT JÚNIOR, 2013, p.13).

Por outro lado, destaca-se que a visibilidade das populações africanas, indígenas e negras vem ocorrendo em outros espaços de memória e de territórios, tanto em Porto Alegre, por meio do Museu de Percurso, como em outras regiões do Brasil. ${ }^{10}$ Inclusive, com possibilidades de decolonização dos saberes no ensino, como problematizou Carla Meinerz e Carmem Gil (2017) e como elemento de uma educação para a cidadania, como destaca Judite Primo, quando afirma que:

[...] o movimento da nova museologia ou a museologia social e as suas transformações contribuíram para que os museus seguissem o caminho para a sua aproximação do modelo de fóruns, sítios de encontros, de diálogos, de debates e de ações museológicas comprometidos com a memória, com o patrimônio e com a mudança social (PRIMO, 2014, p.07).

Essa mudança possibilita a proliferação dos ecomuseus e dos museus de sociedade. Esses pretendem ser "o espelho em que a população se olha para se reconhecer nesse espaço, no qual ela procura a explicação do território a que está vinculada, conectada com a história das populações precedentes" (POULOT, 2013, p.56).

As transformações possibilitadas pela Museologia Social vão além, pois como assevera Dominique Poulot:

A lógica comunitária do projeto é definida pela territorialidade do campo de intervenção e pela participação da população que passa de consumidor do museu para a função de ator e autor do museu. As noções, e os valores, de território, patrimônio e população opõem-se aí, termo a termo, às noções e aos valores de edifício, coleção e público (POULOT, 2013, p.53)

\footnotetext{
${ }^{10}$ Museu Nacional da Cultura Afro-Brasileiro em Salvador (BA), Memorial Mãe Menininha do Gantois em salvador (BA), Casa do Benin em Salvador (BA), Memorial das Baianas em Salvador (BA), Museu da Abolição em recife (PE), Museu Afro-Brasil, em São Paulo (SP), Museu Afro-Brasileiro (SE), Museu do Negro (RJ), Museu 13 de Maio, em Santa Maria (RS), Museu do Percurso do Negro, em Porto Alegre (RS), Território Negros de Porto Alegre (RS), Museu Kuahí dos Povos Indígenas do Oiapoque, em Macapá (AP), Museu Indígena, em Coroa Vermelha (BA), Museu Magüta dos Índios Ticuna em Benjamin Constant (AM). (MEINERZ; GIL, 2017, p.25).
} 
Em 1984 na cidade de Quebec no Canadá, em decorrência dos debates da renovação da museologia, ocorreu uma crítica ao distanciamento dos Museus com a sociedade, repercutindo uma discussão sobre o Museu e a Educação que devem estar voltados para a participação, reflexão, mobilização e transformação social, além da reformulação de espaços físicos e exposições (VILASBOAS, 2010).

\section{O ENSINO DE HISTÓRIA E A PRÁTICA EDUCATIVA DECOLONIAL NO MUSEU DE PERCURSO}

O convite para ser "Instrutor de História" da primeira etapa das atividades do Museu do Percurso do Negro ocorreu em outubro de 2009 pela coordenadora pedagógica do projeto, Sandra Helena Maciel, integrante do GT Angola Janga. ${ }^{11}$

Segundo Maciel:

O Museu de Percurso do Negro em Porto Alegre, em sua concepção, prevê a capacitação de jovens negros, indicados pelas entidades que fazem parte do conselho gestor. Foram 18 jovens selecionados, inicialmente. Esses jovens tiveram aulas durante seis meses, de História do Movimento Negro, Turismo Étnico, Territórios Negros em Porto Alegre e Cooperativismo [...] (MACIEL, 2010) $)^{12}$.

Em contrato de prestação de serviços autônomos, celebrados por mim e pelo GT Angola Janga; representada por seu coordenador executivo, Flávio Eduardo Neves Teixeira, ficou acertado que os encontros seriam realizados pelo período de 22 de outubro a 26 de novembro de 2009, com 30 horas-aula. ${ }^{13} \mathrm{Na}$ função, eu deveria ministrar a disciplina de "História e Formação Urbana de Porto Alegre” para 18 monitores do projeto. Nessa primeira etapa, os monitores a serem formados foram jovens negros e negras moradores dos bairros periféricos de Porto Alegre, selecionados diretamente pelas organizações negras apoiadoras. ${ }^{14}$

\footnotetext{
${ }^{11} \mathrm{O}$ convite para atuar no projeto provavelmente tenha decorrido de minha inserção junto aos movimentos sociais negros, já que desde o ano de 2003 desenvolvi e organizei, ao lado de Lúcia Regina Brito Pereira e Luiz Carlos Amaro, in memorian, todos como membros do GT Negros da Associação Nacional de História - Seção RS, cursos, encontros e seminários no Memorial do Rio Grande do Sul, sobre temáticas das populações negras. Esses cursos ganharam visibilidade, já que foram realizados de 2003 a 2011, atingindo inúmeros acadêmicos e militantes sociais do Estado e de outras partes do País.

12 Disponível em: <http://museudepercursodonegroemportoalegre.blogspot.com.br/p/textos.html>. Acesso 21 jan.2018.

${ }^{13}$ Contrato de Prestação de Serviços Autônomos do Museu do Percurso do Negro. Porto Alegre, 22 de outubro de 2009.

${ }^{14}$ Os alunos foram instigados a produzir seus saberes a partir de suas vivências e de seu presente, procurando, por meio das interpretações das fontes, possíveis compreensões sobre as construções do passado. Como assevera
} 
Fronteiras: Revista de História

Ensino de História, Patrimônio e Práticas Educativas Decoloniais no Museu de Percurso do Negro de Porto Alegre - Arilson dos Santos Gomes

O programa de Ação Cultural Educativa do Museu de Percurso tem como um de seus objetivos a capacitação de jovens negros de bairros periféricos de Porto Alegre para atuarem como monitores dos roteiros do museu além de desenvolver projetos voltados à comunidade que mora no entorno de cada marco, buscando assim fomentar a relação de identificação da comunidade com o museu (VILASBOAS, 2010).

A atribuição dos monitores/guias foi exercida por meio da mediação de visitas públicas guiadas ao roteiro do Museu do Percurso do Negro e incluiu a apresentação de marcos, o contexto histórico dos locais em que os monumentos foram erguidos e a história de Porto Alegre envolta às territorialidades negras.

O primeiro marco construído do museu foi a obra o Tambor, inaugurada no dia 9 de abril de 2010. Os adolescentes monitores do Museu de Percurso do Negro, capacitados nas oficinas, seguiram diversos percursos e, durante a realização do Fórum Social Mundial de 2010 na cidade, apresentaram a obra aos visitantes (BITTENCOURT JÚNIOR, 2010).

“O tambor é um agente de comunicação e símbolo de preservação da unidade social, cultural e política das comunidades negras [...]” (BITTENCOURT JÚNIOR, 2010, p.118-119). O marco foi decidido entre os artistas plástico Leandro Machado, Gutê e Pelópidas Thebano, Adriana Xaplin e Marcos Mattos. "O monumento do Tambor foi elaborado em grupo, resultado de como os artistas e imemoriais afro-brasileiros, ao cartografar esteticamente os passos dos negros em terras brasileiras [...]” (BITTENCOURT JÚNIOR, 2010, p.129). O Tambor está situado na Praça Brigadeiro Sampaio, antigo local Público da Forca, onde muitos negros condenados por desobediência ao sistema escravocrata eram mortos. Essas informações são repassadas pelos guias formados pelo projeto.

\footnotetext{
Almeida (2013), deve ser observada a relação sujeito e objeto de conhecimento (a identidade entre sujeito e objeto).
} O sujeito não é mais elemento passivo nem simples receptáculo no processo cognitivo. 
Fronteiras: Revista de História

Ensino de História, Patrimônio e Práticas Educativas Decoloniais no Museu de Percurso do Negro de Porto Alegre - Arilson dos Santos Gomes

Imagem 01. Etapa 01 do Museu, inaugurada no dia 09 de abril de 2010. Monumento O Tambor

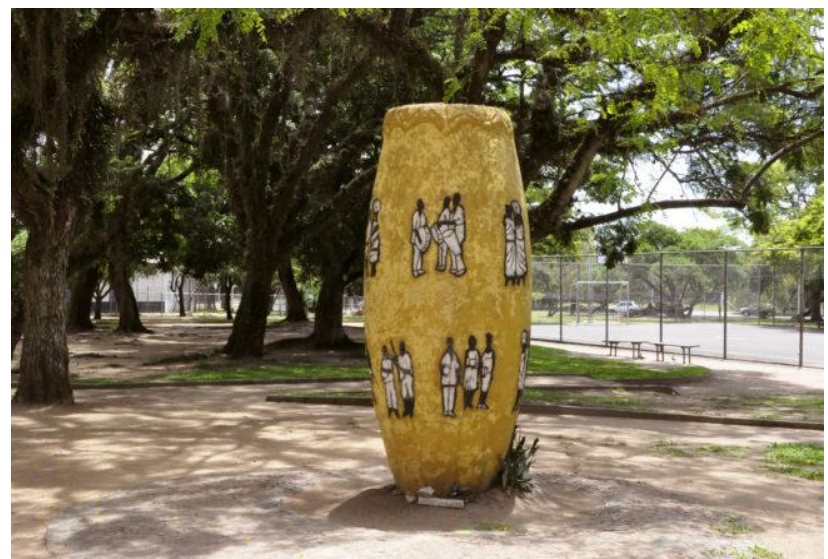

Fonte: Disponível em: <http://g1.globo.com/rs/rio-grande-do-sul/noticia/2016/11/museu-de-percursodo-negro-resgata-memoria-e-territorios-em-porto-alegre.html>. Acesso 22 jan. 2018>.

As aulas com os jovens foram realizadas na Escola de Saúde Pública. Durante um mês, os participantes desenvolveram atividades que os possibilitaram compreender a trajetória e a participação das comunidades negras na formação urbana da capital do Estado do Rio Grande do Sul.

Uma das estratégias de ensino foi a interpretação de fotografias antigas da cidade Porto Alegre, datadas de meados do século XIX. Nas imagens visualizavam-se os sujeitos negros (as) vendendo produtos no mercado central, construindo prédios, trabalhando como estivadores e abrindo as principais ruas e avenidas da cidade. Na próxima imagem é possível observar a região do Mercado Central da cidade e a Praça XV, local de comércio, de trabalho e de circulação das populações negras.

Imagem 02. Região do Mercado Público Central de Porto Alegre no século XIX

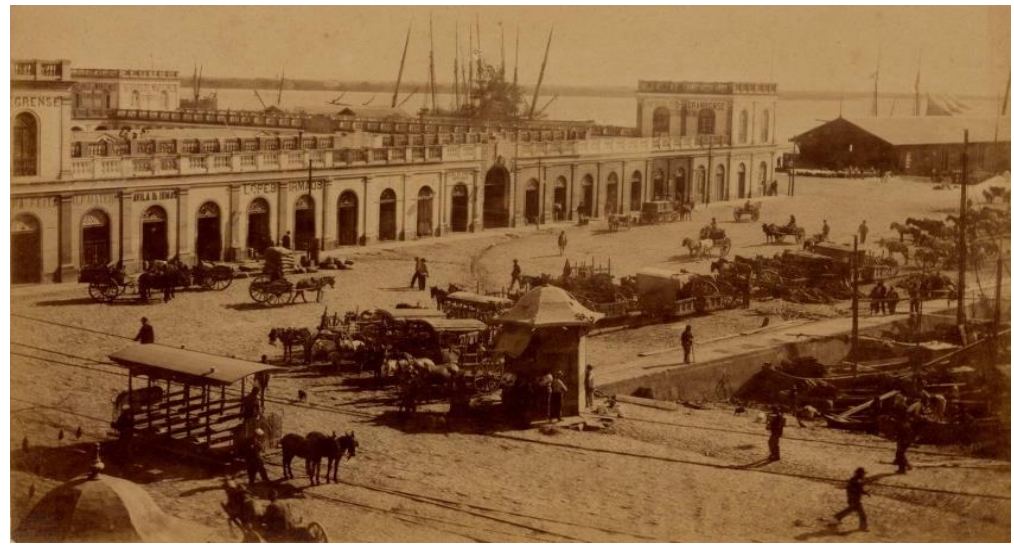

Fonte: Disponível em: <https://www.ufrgs.br/jornaisliterarios/acervodigital/porto-alegre-no-seculo-xix/foto697f/. Acesso: 25 Fev. 2018. 
Conforme Iosvaldyr Bittencourt Júnior (2010), a partir dessas constatações, analisa-se Porto Alegre quanto às possibilidades da mobilidade negra nas cidades, a exemplo das vendedoras do Largo da Quitanda:

É possível perceber a ampla circularidade e domínio dos lugares públicos urbanos que detinham as negras vendedoras. Se a quitanda a obrigava a uma fixidez, onde acolhia inúmeros clientes, o tabuleiro conferia-lhe uma ampla mobilidade, bem como as visitações para vendas feitas de porta em porta. Estas condições de trabalho oportunizavam às negras vendedoras múltiplos contatos com os demais escravos. Seja nas ruas ou nas casas, bem como com segmentos brancos da população porto-alegrense [...] a tenacidade da autopreservação fazia com que os ganhos conseguidos com os serviços diários fossem acrescidos de pequenas transgressões, facilitadas pelas redes de solidariedade e interesses mútuos que se cruzavam (BITTENCOURT JÚNIOR, 2010, p. 37).

Imagem 03. Imagem ilustrativa da mulher negra quitandeira no século XIX

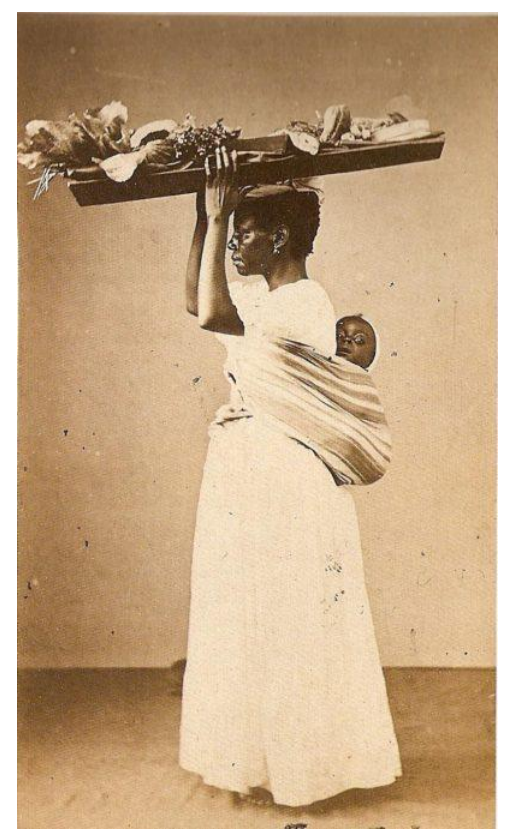

Fonte: Disponível em: < https://jornaldomercado.com.br/as-negras-minas/. Foto: Christiano Júnior. Acesso: 24 Nov. 2019.

A cada percepção da participação das populações negras na história da cidade surgiam reflexões e satisfações em conhecer outra versão da história, longe de estigmas, a exemplo de uma epistemologia de fronteira ou contra um pensamento abissal, como destaca Boa Ventura Souza de Santos (2010). Pensamento abissal que, em última análise, relacionou as populações negras a sujeitos sem vontade e sem protagonismos. 
Nessa sequência, o trabalho colabora para a criação de outra epistemologia. Diferente daquela versão ocidental difundida na modernidade, em que a apropriação e a violência criaram seres civilizados e primitivos (SANTOS; MENEZES, 2010). Situação que guardadas as proporções insistem em permanecer sobre os motes do preconceito e do racismo atualizados sobre os povos negro-africanos e os seus descendentes. Como aponta Mignolo (2008), esses grupos, como os asiáticos e os indígenas, entre outros subalternizados, tiveram suas línguas, religiões e formas de pensar e agir marginalizadas. Porém, “essas histórias e culturas estão sendo re-inscritas em confrontação com as categorias de pensamento do ocidente. Pensamento de fronteira ou epistemologia de fronteira é uma das consequências e a saída para evitar tanto o fundamentalismo ocidental quanto o não-ocidental" (MIGNOLO, 2008, p.297). Pois, referenciar a trajetória da população negra de maneira crítica não significa deslocar a sua trajetória dos assuntos humanos, como no passado colonial que não via esse grupo como um construtor e sujeito de ações. Algo, que precisava ser tencionado.

Por isso, a proposta incorporou outras fontes e linguagens no ensino de história, como salienta Selva Fonseca (2009) ao destacar, em seu importante estudo, o uso da educação patrimonial articulada ao ensino e à aprendizagem de história, tornando-a mais atrativa e potencializando o despertar da consciência histórica dos jovens. ${ }^{15}$

Além disso, concordando com Gonzaga (2016) os usos políticos do tempo, como seus usos na educação patrimonial, poderão constituir como estratégias necessárias para irromper a transição eurocêntrica pela qual a experiência colonial no tempo foi definida. Portanto, A iniciativa juntos aos monitores do trata-se de uma perspectiva decolonial (MIGNOLO, 2008) para se pensar e transmitir um conhecimento advindo de povos que foram subalternizados e que constroem, por meio da valorização de sua cultura, no presente uma identidade negra positiva (GOMES, 2005). Ao final dos trabalhos, dos 18 jovens que iniciaram o curso, 15 se formaram como monitores/guias da primeira etapa do museu.

Em 2014, novamente tive a oportunidade de compor a equipe da quarta etapa do Projeto do Museu, agora sob a coordenação pedagógica de Elza Vieira da Rosa. ${ }^{16}$ Esse

\footnotetext{
15 Rüsen (2001) entende por consciência histórica a soma das operações mentais com as quais os humanos interpretam sua experiência e a evolução temporal de seu mundo e de si mesmos de forma tal que podem orientar, intencionalmente, a sua vida prática no tempo (RÜSEN, 2001). “A consciência histórica, portanto, está fundada nessa ambivalência antropológica: o homem só pode viver no mundo, isto é, só consegue relacionar-se com a natureza, com os demais homens e consigo mesmo se não tomar o mundo e a si mesmos como dados puros, mas sim interpretá-los em função de suas ações e paixões" (RÜSEN, 2001, p.58-59), de sua intencionalidade.

${ }^{16}$ A equipe do Museu de Percurso do Negro é formada por Pedro Rubens Vargas, Técnico Cultural e Pesquisador; Jeanice Dias Ramos, Museóloga e Bibliotecária; Iosvaldyr Bitencourt Jr., Antropólogo e Jornalista; Veneza Bitencourt, Presidente do Angola Janga; Pelópidas Thebano, Pintor e Desenhista; Gutê, Escultor; Vinícius Vieira, Escultor, Arquiteto e Urbanista; Ivan Braz, Administrador; Lorecinda Ferreira Abrão, Gestora; Leandro Machado,
} 
momento é tratado neste artigo como uma educação em um espaço informal, já que os encontros foram nos espaços da Associação Comunitária do Quilombo urbano Areal da Baronesa, sendo os futuros monitores jovens moradores do quilombo. ${ }^{17}$

A realização da quarta etapa do Museu de Percurso contou com recursos oriundos do Prêmio Funarte de Arte Negra/Ministério da Cultura e Secretaria de Políticas Públicas da Igualdade Racial, e incluiu a execução da obra de arte pública Painel Afro-brasileiro, além do lançamento de um catálogo e da formação de monitores no Quilombo do Areal da Baronesa. ${ }^{18}$

Durante três meses - entre julho e setembro do ano de 2014 - foram realizadas, com os jovens, oficinas sobre "História da identidade negra e da cultura afro-brasileira". A diferença da primeira etapa de formação para essa foi que o público a ser formado era composto exclusivamente por jovens quilombolas residentes no Areal.

O conceito contemporâneo de quilombo leva em consideração a presença de comunidades ou agrupamentos cujas práticas cotidianas na manutenção e reprodução de seus modos de vida característicos contribuam para a consolidação de um território próprio, valorizando elementos como histórias de resistências, experiências coletivas e diferentes trajetórias históricas e políticas de determinada coletividade (LEITE, 2004).

Na próxima imagem é possível visualizar a apresentação da Equipe responsável pela formação dos monitores, segurando a bandeira do GT Angola Janga. Esse encontro ocorreu em junho de 2014, na sede comunitária do Quilombo do Areal da Baronesa, com muito entusiasmo por parte dos responsáveis e presença marcante dos meninos e das meninas residentes do quilombo urbano.

Artista Visual; Sandra Helena Maciel, Coordenadora Pedagógica (2009-2010); Adriana Xaplin, Artista Visual; Elza Vieira da Rosa, Coordenadora Pedagógica (2014); Arilson dos Santos Gomes, Historiador; Paulo Corrêa, Fotógrafo; João Lucas, Arte-educador; Ubirajara Toledo, Coordenador Executivo do Iacoreq; Mãe Norinha de Oxalá, Presidente da Cedrab RS; Flávio Eduardo Neves Teixeira, Engenheiro; Mattos, Ilustrador; Maria Elaine Rodrigues, Presidente da Mocambo.

${ }^{17}$ Segundo Sandra Pesavento (1999), o espaço mais característico da estigmatização urbana de Porto Alegre foi aquele designado por "Areal da Baronesa". O termo designava a antiga chácara da Baronesa do Gravataí, vasta área que cumpria um papel próximo ao das citadas "emboscadas": em parte cobertas por um matagal espesso, as terras da Baronesa do Gravataí eram procuradas pelos negros fugidos da escravidão, que lá iam se esconder (PESAVENTO, 1999). O Quilombo Areal da Baronesa foi reconhecido em 2004 pela Fundação Palmares e em 2014, finalmente, titulado pelo Incra. O primeiro quilombo urbano do país a receber o diploma de titulação, foi o Quilombo da Família Silva, de Porto Alegre, em 2009.

${ }^{18}$ Sobre a origem dos quilombos no Estado do Rio Grande do Sul, tem-se no trabalho das charqueadas uma larga utilização do trabalho escravo, assim como em outras áreas produtivas. Isso contribuiu para que o contingente populacional, formado por ex-escravos, tivesse restringido o acesso às diversas formas de produção econômica e de bens passíveis de gerar lucro, renda e conquistar autonomia econômica e social. Os ex-escravos e seus descendentes estabeleceram domínios territoriais nos mais variados rincões do Rio Grande do Sul e preservaram características consideradas singulares e próprias desses agrupamentos étnicos remanescentes da escravidão. Essas comunidades são designadas, atualmente, como remanescentes de quilombos (SILVA, 2010). 
Fronteiras: Revista de História

Ensino de História, Patrimônio e Práticas Educativas Decoloniais no Museu de Percurso do Negro de Porto Alegre - Arilson dos Santos Gomes

Imagem 04. Apresentação da $4^{\mathrm{a}}$ Etapa do Museu na Sede da Associação do Quilombo do Areal

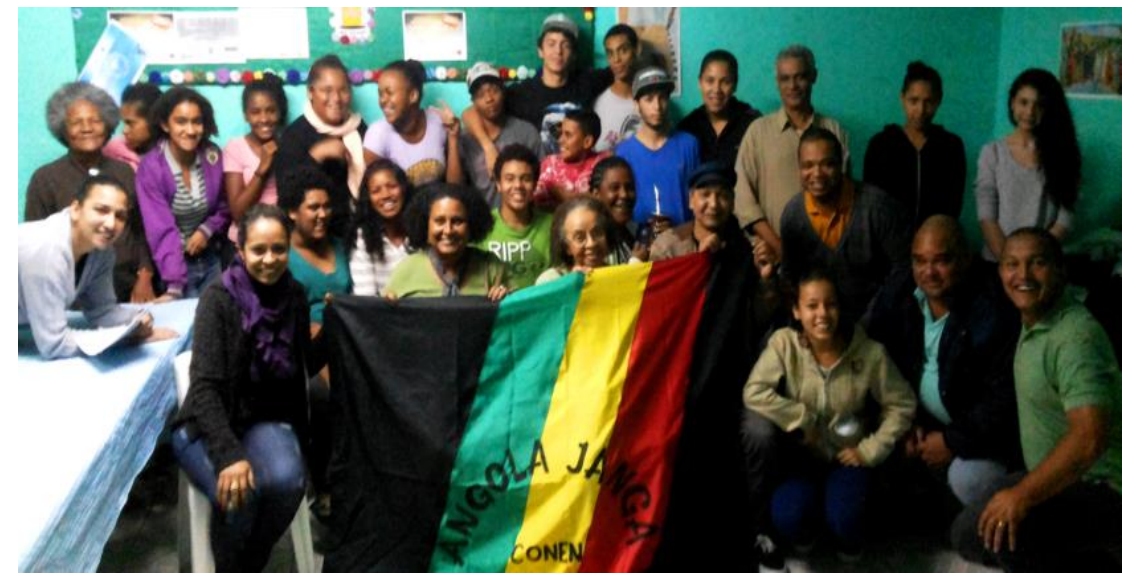

Fonte: Disponível em: http://museudepercursodonegroemportoalegre.blogspot.com.br/p/artepublica.html>. Acesso: 11 Jan. 2018.

Desde os primeiros instantes, percebeu-se a necessidade de interagir de maneira dinâmica com os meninos e as meninas que teriam a incumbência de orientar o público visitante do Museu de Percurso. ${ }^{19}$ Como destacam Maria Auxiliadora Schimidt e Marlene Cainelli:

[...] ensinar história hoje pressupõe ter o tempo como significante para que o sujeito, a partir de temporalidades diversas, possa perceber que aprender história é reconhecer em outros tempos e sujeitos experiências, valores e práticas sociais. É propiciar ao aluno reconhecer-se enquanto sujeito do seu tempo e com isto conseguir que ele reconheça outros sujeitos em tempos diversos. (SCHIMIDT; CAINELLI, 2010, p. 106).

No início, notou-se que os jovens quilombolas, mesmo sendo moradores de um território de resistência - o Areal da Baronesa, reconhecido quilombo urbano - estavam distantes de seu pertencimento identitário, não como moradores de um espaço histórico propriamente dito, mas de uma identidade altiva, assertiva e protagonista. ${ }^{20}$

Portanto, essa situação gerou dois desafios. O primeiro relacionado ao fortalecimento de suas autoestimas e, o segundo vinculado ao seu conhecimento sobre a identidade negra quilombola. Identidade construída ao longo de séculos por meio das organizações negras, bem

\footnotetext{
${ }^{19}$ Foram escolhidos 17 alunos por intermédio da Associação Comunitária do Quilombo do Areal. Todos os participantes da oficina eram matriculados no turno da manhã em escolas da rede pública de Porto Alegre; por isso, as formações ocorriam à tarde, no turno inverso. Nos encontros, eles tinham lanches e ao final de cada mês recebiam uma bolsa auxílio destinada pelos financiadores da $4^{a}$ Etapa do Museu de Percurso do Negro.

${ }^{20}$ Em Porto Alegre, existem quatro quilombos originários de populações historicamente invisibilizadas e alijadas do poder, entre o final do século XIX e XX, que foram retiradas da área central formando os territórios do Areal da Baronesa e a Comunidade dos Alpes; ou egressos de outras cidades do interior onde também encontraram os mesmos entraves às necessidades básicas, como o acesso ao trabalho e às condições dignas de vida. A exemplo, o casal que deu origem à família Silva e, mais recentemente, à família Fidélix (GEHLEN; RAMOS, 2008).
} 
como pelas ações de homens e de mulheres (individualmente ou coletivamente) que, motivados contra os estigmas e os estereótipos advindos com os séculos de escravidão, como diz Homi Bhabha (2007), mantiveram a resiliência na luta por dias melhores, propondo a afirmação de seu pertencimento étnico, político, cultural e econômico em uma sociedade desigual.

Compreendeu-se que essas atividades deveriam ser qualificadas e não superficiais em torno de um conhecimento totalizante ou insuflador da negritude exacerbada e particularizada, mas sim de uma negritude política, com elementos para a compreensão da historicidade de ser negro em um mundo composto por tantos outros grupos étnicos. ${ }^{21}$

Nesse sentido, optou-se por trabalhar conceitualmente termos como cultura, identidade, quilombo, africanidades, ações afirmativas e territorialidade no intuito de instrumentalizar esses jovens para exercerem as suas cidadanias, além de informar aos visitantes sobre os territórios simbólicos por que passaram as comunidades negras em Porto Alegre, representados nas obras já monumentalizadas do Museu, como o Bará do Mercado Público, o Tambor, a Pegada Africana e o Painel Afro-Brasileiro, que estava em fase de elaboração.

As oficinas tiveram os seguintes objetivos: 1) despertar os seus participantes ao entendimento dos termos e conceitos utilizados à compreensão das relações étnico-raciais; 2) demonstrar as lutas históricas de grupos e indivíduos negros para a afirmação de sua identidade e na busca por seus direitos; 3) explicar como ocorreu a vinda forçada dos africanos para o Rio Grande do Sul e abordar as influências dos povos africanos em nosso cotidiano, do passado à atualidade e 4) contextualizar os territórios constitutivos do Museu do Percurso do Negro em Porto Alegre.

Os resultados das oficinas foram interessantes já que, a cada encontro, observava-se nos olhos dos quilombolas o brilho da descoberta proporcionado por suas participações autônomas, ocorridas por meio dos relatos de suas experiências cotidianas mediados pelos temas propostos à oficina. Ressalta-se que os conceitos não foram somente teorizados, até porque esses adolescentes, entre 10 e 15 anos de idade, estavam no início ou no meio de suas formações escolares básicas. Esses conceitos foram utilizados para se refletir sobre acontecimentos reais, embasados nas relações sociais existentes em suas escolas e em sua comunidade. Em conformidade com Paulo Freire (1996), se compreende a educação como uma

\footnotetext{
${ }^{21}$ Com a promulgação da Constituição Federal de 1988, o artigo 68 reconheceu o direito das terras aos remanescentes de quilombos, atualmente, os representantes dessas demandas se afirmam politicamente como membros da ancestralidade negro quilombola (MATTOS, 2006).
} 
forma de participação e intervenção no mundo, devido a isso os encontros foram dinâmicos já que o conteúdo era em grande parte produzido por experiências. Com isso, as vivências dos participantes foram transformadas em conteúdos para o entendimento dos conceitos.

Por vezes, durante as oficinas, eram convidados os mais velhos do Quilombo do Areal para contar histórias de suas vidas e do território. Nesse sentido, aprendemos uns com os outros. Como aduz Kruppa (2006) a educação aqui é entendida como troca e diálogo entre e intergerações, garantindo que homens e mulheres retransmitam esses conhecimentos uns aos outros.

A conclusão das oficinas ocorreu na Secretaria Municipal da Juventude de Porto Alegre. Ao todo, 16 quilombolas se formaram como monitores da quarta Etapa do Museu de Percurso do Negro.

A seguir, é possível visualizar a inauguração do Painel Afro-Brasileiro, localizado no Largo Glênio Peres, antiga Praça XV no Centro de Porto Alegre, em frente ao Mercado Público Central. Um dos espaços onde os monitores quilombolas formados passaram a conduzir a visitação ao público visitante. O painel está em um local em que, no passado, antes da abolição, os negros e as negras porto-alegrenses comercializavam produtos na região, um território constituído por inúmeras relações coletivas de sobrevivência e de resistência (BITTENCOURT JÚNIOR, 2010).

Imagem 05. Quarta etapa, inaugurada no dia 20 de novembro de 2014 no Centro de Porto Alegre - RS

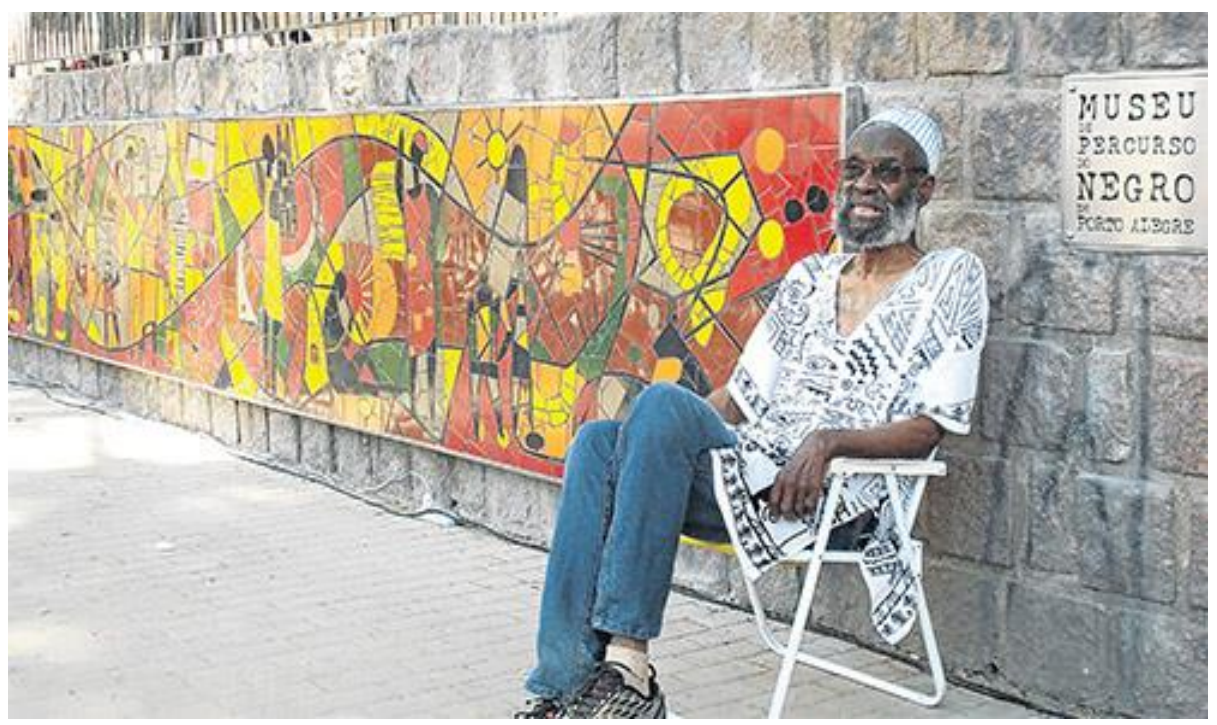

Fonte: Painel Afro-Brasileiro e o artista Pelópidas Thebano. A concepção do painel ficou a cargo do artista Pelópidas Thebano e a execução foi feita pelo arquiteto Vinicius Vieira. Disponível em: <https://jornaldomercado.com.br/wp-content/uploads/2014/12/painel-afro-bresileiro.jpg > 
A partir das conversas com os quilombolas integrantes do projeto, teve-se a convicção de que todos compreenderam as informações e as dinâmicas propostas, já que, ao final de cada encontro, solicitava-se um relato a partir de suas experiências sobre os temas trabalhados. Assim, constituíram-se outras ferramentas de saber às suas percepções de serem negros quilombolas conscientes de seu passado e sujeitos ávidos de agir em seu presente para qualificarem os seus futuros e, assim, assumirem e reproduzirem o protagonismo da história de sua comunidade na cidade de Porto Alegre.

\section{CONCLUSÃO}

Por meio das atividades do Museu de Percurso do Negro de Porto Alegre à luz da Museologia Social, os jovens negros e negras da periferia e do Quilombo urbano do Areal da Baronesa tiveram acesso a um projeto que os possibilitou conhecer a trajetória de sua comunidade e a elevar a sua autoestima. Desse modo, foi possível auxiliá-los na monitoria a ser realizada ao público visitante dos marcos do museu que versa sobre a trajetória da comunidade negra em uma capital. Nada mais interessante e justo que os agentes operantes dessa visita realizassem a mediação a partir dos marcos monumentalizados ao público, já que esses monitores não são meros espectadores de uma história congelada ou de uma identidade fixa, como demonstrou esse trabalho. Eles carregam e são membros da comunidade negra e remanescentes de quilombos com passado e presente, sendo as suas vivências legítimas para a execução de uma atividade propiciada e instauradas a partir das demandas das populações negras em sua luta cotidiana por cidadania. Ademais, esses jovens são protagonistas, são sujeitos.

As visitações ao Museu de Percurso do Negro, além da mediação exercida por monitores capacitados, são igualmente realizadas por meio de visitas espontâneas efetuadas por acadêmicos e populares, bem como por docentes e discentes de escolas e de universidades públicas e privadas. Outra maneira de visitar os espaços é por meio do agendamento realizado com a empresa de ônibus Carris de Porto Alegre junto ao projeto "Territórios Negros", em que espaços da cidade e os monumentos do percurso são visitados com o apoio de monitores contratados pela prefeitura. Situação que evidencia, a partir da promulgação da Lei 10.639/03, o crescente interesse em se conhecer a trajetória das populações negras de maneira decolonial e assertiva na capital mais ao Sul do Brasil Meridional. 


\section{REFERÊNCIAS}

ALMEIDA, Rodrigo Davi. Ser Professor de História: A Importância da Fundamentação Teórica da Prática Docente. Disponível na World wide web: < http://historiaehistoria.com.br/materia.cfm?tb=professores\&id=157>.

BITTENCOURT JÚNIOR, Iosvaldyr Carvalho. (Org). Os Percursos do Negro em Porto Alegre: territorialidade negra urbana. In: Museu de Percurso do Negro em Porto Alegre. Porto Alegre: Porto Alegre: Ed. Porto Alegre, 2010.

BITTENCOURT JÚNIOR, Iosvaldyr Carvalho. As representações do negro nos museus do Rio Grande do Sul são marcadas pela invisibilidade simbólica: do "resgate" afro-brasileiro às pesquisas histórico-antropológicas a às visibilidades negras na museologia. In. Museus e Africanidades. Porto Alegre: EDIJUC, 2013.

BHABHA, Homi. O local da Cultura. Belo Horizonte: Editora UFMG, 2007.

BRASIL. Ministério da Educação/Secad. Diretrizes curriculares nacionais para a educação das relações étnico-raciais e para o ensino de história e cultura afro-brasileira e africana na educação básica. 2004.

BRASIL. Lei 10.639/03. Altera a Lei no 9.394, de 20 de dezembro de 1996, que estabelece as diretrizes e bases da educação nacional, para incluir no currículo oficial da Rede de Ensino a obrigatoriedade da temática "História e Cultura Afro-Brasileira".

\section{CONSTITUIÇÃO DA REPÚBLICA FEDERATIVA DO BRASIL DE 1988.}

FONSECA, Selva Guimarães. A avaliação do ensino e da aprendizagem. Fazer e Ensinar História. Belo Horizonte: Dimensão, 2009.

FREIRE, Paulo. Pedagogia da Autonomia. Saberes necessários à prática educativa. Rio de Janeiro: Paz e Terra, 1996.

GEHLEN, Ivaldo; RAMOS, Ieda Cristina Alves. Estudo quanti-qualitativo da População Quilombola do Município de Porto Alegre/RS. Porto Alegre: UFRGS, 2008.

GIL, Carmem ZelideVargas; MEINERZ, Carla Beatriz. jan./abr. 2017. Educação, patrimônio cultural e relações étnico-raciais: possibilidades para a decolonização dos saberes. Revista Horizontes, 35 (1):19-34.

GOMES, Arilson dos Santos. 2017. Africanidades e diversidades no ensino de História: entre saberes e práticas. Educ. rev. Curitiba. (64):189-214.

GOMES, Arilson dos Santos. Ensino e práticas educativas no Museu de Percurso do Negro de Porto Alegre (2009-2014). In: Eulália Maria Aparecida de Moraes; Otávio Ribeiro Chaves; 
Ricardo Tadeu Caires Silva. (Org.). O ensino de história da África e da cultura afro-brasileira e indígena: múltiplos olhares. Cáceres: UNEMAT, 2018.

GOMES, Arilson dos Santos. Quilombolas e educação: vivências de ações afirmativas em três regiões brasileiras. Revista Métis Educação e Cultura, v 17, n³3, UCS, 2018. Disponível em: Acesso em Maio.2019.

GOMES, Nilma Lino. Alguns termos e conceitos presentes no debate sobre relações raciais no Brasil: uma breve discussão. In: Coleção educação para todos. Brasília, DF: SECAD/MEC, 2005.

GONÇALVES, José Reginaldo Santos. Antropologia dos objetos: coleções, museus e patrimônios Rio de Janeiro: Garamond, 2007.

GONZAGA, Gabriel. 2015. Territórios negros: patrimônio, diáspora e tempo. Revista Historia e Diversidade, UNEMAT, Vol. 7, nº 2. 54-72.

KRUPPA, Sonia Maria Portella. Educação e o mundo do trabalho. Brasília: MEC, 2005.

LEITE, Ilka Boaventura. 2000. Os quilombos no Brasil: questões conceituais e normativas. Revista Etnográfica, Lisboa, 4 (2):333-354.

MACIEL, Sandra Helena Figueiredo. Capacitação de jovens negros. Porto Alegre, 2010. isponível na World wide web:

http://museudepercursodonegroemportoalegre.blogspot.com.br/p/textos.html >.

MATTOS, Hebe. "Terras de Quilombo: campesinato, memória do cativeiro e identidade negra no Rio de Janeiro". In: Trabalho Livre Trabalho Escravo. 1 ed. Belo Horizonte: Annablume, v $1,2006$.

MATTOS, Jane Rocha de. (Org.). Museus e Africanidades. Porto Alegre: EDIJUC, 2013.

MIGNOLO, Walter. Desobediência epistêmica: a opção descolonial e o significado de identidade em Política. Trad. Ângela Lopes Norte. Cadernos de Letras da UFF - Dossiê: Literatura, língua e identidade, no 34, p. 287-324, 2008.

PESAVENTO, S. J. Set. 1999. Lugares malditos: a cidade do "outro" no Sul brasileiro (Porto Alegre, passagem do século XIX ao século XX). Revista Brasileira de História. São Paulo, 19 (37).

POULOT, Dominique. Museu e museologia. Belo Horizonte: Autêntica editora, 2013.

PRIMO, Judite. 2014. O social como objecto da museologia. Cadernos de Sociomuseologia, 3 (47):5-28. 
RODRIGUES, Lizandra Maria Rodrigues Machado; ZUBARAN, Maria Angélica. Representações racializadas de negros nos museus: o que se diz e o que se ensina. In: Museus e Africanidades. Porto Alegre: EDIJUC, 2013.

ROSA, Elza Vieira da. O Museu do Percurso do Negro de Porto Alegre: interrompendo invisibilidades, reinscrevendo experiências negras na cidade. Dissertação de Mestrado em Sociologia - PPGS. Porto Alegre. UFRGS, 2019.

RUPPENTHAL, Franciele Renata. Um percurso vivido: pluralizando histórias e memórias a partir do projeto "Territórios Negros". Revista Ciências Sociais Unisinos, mai/ago 2016, Vol. $52, \quad$ N. 2, p. 162-171. Disponível na World wide web:< http://revistas.unisinos.br/index.php/ciencias_sociais/article/view/csu.2016.52.2.03/5476>.

RÜSEN, Jörn. A Razão histórica. Brasília: UnB, 2001. p.95-126.

SANTOS, Boaventura de Sousa; MENESES, Maria Paula. (Orgs.) Epistemologias do Sul. São Paulo: Editora Cortez. 2010.

SILVA, Paulo Sérgio da. Mediação social e políticas públicas nas comunidades remanescentes de quilombos do Rio Grande do Sul. In: RS Negro - Cartografias sobre a produção do conhecimento. Porto Alegre: EDIPUCRS, 2008.

SCHIMIDT, Maria Auxiliadora; CAINELLI, Marlene. Construção de conceitos históricos, as construções de noções de tempo e as fontes históricas no ensino da História. Ensinar História. São Paulo: Scipione, 2010.

SOARES, Karitha Regina. 2017. Da forca ao tambor: o Museu do Percurso como reconhecimento histórico da presença do negro na formação da cidade de Porto Alegre. Trabalho de Conclusão de Curso em História. Porto Alegre. UFRGS - Karitha Regina Soares.

VARGAS, Pedro Rubens. O Museu de Percurso do Negro na perspectiva de seus idealizadores: os militantes do Movimento Negro. In: Museus e Africanidades. Porto Alegre: EDIJUC, 2013.

VIEIRA, Daniele Machado. Percursos negros em Porto Alegre: ressignificando espaços, reconstruindo geografias. ANAIS do VII Congresso Brasileiro de Geógrafos. Vitória - ES, 2014. Disponível na World wide web: http://www.cbg2014.agb.org.br/resources/anais/1/1404663795_ARQUIVO_DanieleMVieira. CBG2014.pdf>.

VILASBOAS, Ilma Silva. Projeto Museológico e Museográfico. In: Museu de Percurso do Negro em Porto Alegre. Porto Alegre: Ed. Porto Alegre, 2010.

Recebido em: 14/11/2019

Aprovado em: 07/04/2020 